\title{
Investigating rapid deforestation and carbon dioxide release in Bangladesh using geospatial information from remote sensing data
}

\author{
S.N.M. Azizul Hoque ${ }^{1}$, Mondar Maruf Moin Ahmed ${ }^{2}$ and Md. Mafijul Islam Bhuiyan ${ }^{3}$ \\ ${ }^{1}$ Assistant Professor, Department of Physical Sciences, Independent University, Bangladesh (IUB), Dhaka 1229, Bangladesh \\ ${ }^{2}$ Research Trainee, Nutrition and Clinical Services Division, International Centre for Diarrhoeal Diseases Research, Dhaka, Bangladesh \\ (icddr,b) \\ ${ }^{3} \mathrm{Ph} . \mathrm{D}$. Candidate, Department of Physics, University of Alberta, Edmonton, T6G 2E9, Alberta, Canada \\ E-mail addresses: snmhoque@gmail.com,novo24@gmail.com and mbhuiyan@ualberta.ca
}

\begin{abstract}
Rapid deforestation over the last few years due to the massive influx of refugees from neighboring Myanmar has been reported and is seen as a precursor to environmental disaster, raising the need for more effective monitoring of forest areas. The availability of data from several space-borne synthetic aperture radar (SAR) missions allow enhanced monitoring of forest areas. The objective of this study was to map deforestation in two selected areas located in northeast and southeast Bangladesh using Sentinel-1 imageries and determine the applicability of SAR in forest monitoring in Bangladesh. Towards these purpose satellite imageries from 2017 and 2018 collected by Sentinel-1A and Sentinel-1 Band SAR data in dual-polarization mode were used. In the northeastern area of interest, temporary deforestation was detected, which had occurred in low lying areas due to prolonged flooding. The second area of interest, in the southeast, revealed man-made deforestation in high land areas on an immense scale due to the influx and settlement of seven hundred thousand refugees. The results of the two sub-studies demonstrate the applicability and need of SAR data to effectively monitor deforestation in Bangladesh especially as it allows isolating natural and anthropogenic deforestation.
\end{abstract}

Keywords - Remote Sensing, deforestation, ecology, Rohingya refugees

\section{INTRODUCTION}

Deforestation is the destruction and clearing of forest land. In some instances, this occurs as a result of natural disasters, but often it is due to human activity. With a population explosion from just 15 million in prehistory to 7 billion, the demand for land and material for building homes, making furniture, for fuel, food production (meat, soybean and palm oil etc.) has increased manifold, and deforestation has reached disastrous levels globally. Deforestation is also a critical issue in Bangladesh. The country is fast losing its forests and biodiversity: from 1960 to 1990, Bangladesh lost $40 \%$ of its forest land. Since then deforestation has been occurring at an alarming rate of $0.18 \%$ annually. Whereas a country needs $25 \%$ forested area Bangladesh had only 2.3 million hectares in 2015, which is about $15 \%$ (Rahman et al., 2016) and the per capita forest land in the country then was less than 0.01 hectares - insignificant compared to the world average of 0.60 hectares (FAO 2015). Furthermore, of this 2.3 million, primary forest land covered even less: about 1.5 million (FAO 2015). Some experts even fear that the rate of decline has now reached as high as 70,000 hectares annually $(\sim 3 \%)$ and that forest cover has already dwindled from about $15 \%$ to just $5 \%$, leading them to predict that in Bangladesh forest land will disappear within a few decades (Islam et al., 2016; FAO 2015; Rahman et al., 2016). That would lead to a total collapse of the ecosystem. Loss of forest land will hit fauna - the resultant habitat loss will cause abrupt and, maybe, permanent loss of biodiversity. Water cycle would be inhibited which would 
cause gradual desertification and additionally, lack of trees and their roots would result in greater soil erosion.

Furthermore, forests take up and sequester billions of tonnes of $\mathrm{CO}_{2}$, helping to reduce greenhouse gas buildup and thus global warming (Canadell et al., 2008). Forests of Bangladesh have sequestered 127.28 million tonnes $(127280 \mathrm{Gg})$ of carbon and deforestation will lead to its release, increasing the amount of Carbon dioxide $\left(\mathrm{CO}_{2}\right)$, a greenhouse gas, thus raising temperatures. Additionally, loss of trees would lead to lower photosynthesis preventing further sequestration of carbon. Even with high deforestation rates Bangladesh was still considered a low carbon-emitting country in 2015 (FAO 2015). However, the influx of almost a million Rohingyas fleeing ethnic violence in Myanmar since 25 August 2017 (Rahman 2017; Imtiaz 2018) has altered the situation drastically for the worse. These hapless refugees have been housed in camps in forested areas of Teknaf and Rajapalong in the southeast of Bangladesh. By December 2017, there were already an estimated 655,000 to 700,000 refugees (Tani and Rahman, 2017; Imtiaz 2018) and the influx has been marked by massive logging activities in hitherto uninhabited virgin forest area (Hassan et al., 2018; Smith et al., 2018).

One of the foremost duties of the Forest Department (FD) of Bangladesh is monitoring the forests. Monitoring helps identify deforestation, thus directing preventive action. However, traditionally this was done through land and aerial surveys and mapping - a cumbersome and time-consuming process, which hindered timely action. Today, just as weather and flood monitoring is done using weather satellite and GPS data (Hoque and Fenrich, 2018; Hoque and Ahmed 2016; Hoque 2016; Mason et al. 2016; Bhuiyan and Hoque 2020), forest monitoring is also done, in many countries, using geospatial data from sattelite remote sensing (Wagner et al. 2003; Potapov et al. 2017). This type of monitoring can provide precise and timely data and is thus very useful to the FD - and utilization of such monitoring technology is what we propose for protecting forest resources and forest ecosystems and what we aim to demonstrate.

Forest mapping and forest change detection using satellite data can be carried out using different sensors (Dostálová et al., 2016; Quegan et al., 2000; Wagner et al., 2003) including SAR-C and quad polarized PULSAR data. Rahman and Sumantyo used dual-polarized SAR-C data from 1994 and quad polarized PULSAR data from 2007 to successfully map the tropical forest region of southern Bangladesh (Rahman and Sumantyo, 2011). However, this type of SAR imagery is not freely available and so may be costly in the long run for countries like Bangladesh. We have studied SAR (Synthetic Aperture Radar) data from Sentinel-1, a mission from the European Space Agency (ESA) (Sentinel 1, 2017), which are available free of charge.

\section{STUDY METHODOLOGY 2.1 Study sites}

In this paper, we divide our tasks into two sub-studies based on the geographical locations of the areas of interest (AOI). These sub-studies include the monitoring of deforestation over 2017 and 2018 in two locations, one in northeast Bangladesh and the other in southeast Bangladesh. In the first sub-study, carried out in northeast Bangladesh, Khadimnagar National Park and adjoining areas in Sylhet, located $5 \mathrm{~km}$ away from the Osmani International Airport was chosen as AOI, with corner coordinates (i.e., longitudes and latitudes) $\mathrm{NW}\left(91.848078^{\circ}, 25.001340^{\circ}\right), \quad \mathrm{NE}$ $\left(92.065641^{\circ}, 24.998508^{\circ}\right), \operatorname{SE}\left(92.064961^{\circ}, 24.897325^{\circ}\right)$, SW $\left(91.849341^{\circ}, 24.897310^{\circ}\right)$. The location of the AOI is shown in Figure 1, which was created using Google Earth. The area of the park is 678.8 hectares and is slightly raised. However, about 80 ha of the park is low lying and prone to flooding and loss of trees. This was taken as a case of natural deforestation and Sentinel-1 imageries were analyzed to detect flooding and deforestation.

For the second sub-study in southeast Bangladesh, the AOI was in Teknaf and Rajapalong, the site of over a dozen Rohingya camps as shown in Figure 2, which was prepared using Google Earth. The specific areas of interest were the Kutupalong-Balukhali, Uchiprang and Nayapara-Leda areas as most of the Rohingya refugee camps are situated in these areas. The corner coordinates of the AOI were NW $\left(21.394^{\circ}, 92.741^{\circ}\right), \mathrm{NE}\left(21.394^{\circ}, 92.018^{\circ}\right)$, SE $\left(20.888^{\circ}\right.$, $\left.92.018^{\circ}\right), \mathrm{SW}\left(20.888^{\circ}, 92.741^{\circ}\right)$. In this sub-study, the goal was to detect man-made and quite possibly permanent deforestation.

As of 2016, the sizes of the Kutupalong-Balukhali and Nayapara-Leda refugee camps were 146 and 29 ha respectively while in December 2017, they had expanded to 1365 and 133 ha respectively (Hassan et al., 2018). The Uchiprang refugee camps were established after the August 2017 mass influx of Rohingya refugees (Hassan et al., 2018). Recent reports (Hassan et al., 2018, Smith et al. 2018, Imtiaz, 2018) indicate that the area is considered a deforested region.

\subsection{Data acquisition}

Only freely available imageries on the Copernicus open access hub taken by Sentinel-1A, which was launched by ESA (Sentinel-1 2017), were used to study deforestation in both AOIs. Two images were collected for each AOI with the same corner coordinates but two different acquisition dates. Images of the northeast AOI had acquisition dates, March 14, 2017, and September 22, 2017, while the two images of the southeast AOI had acquisition dates, July 2, 2017, and April 28, 2018. All the images collected were of Ground Range Detected (GRD) type, and acquisition mode was Interferometric Wide-Swath (IW). The images were polarized images: VV (vertical transmit-vertical received) and $\mathrm{VH}$ (vertical transmit-horizontal received).

\subsection{Data processing}

After acquisition, the images were cropped to reduce computation time involved in all post-processing steps as well as to minimize storage space requirement. The images 
were processed using SNAP toolbox (SNAP 2018) and an image editing software. The post-processing steps, which comprise the deforestation monitoring system, include radiometric calibration, Lee filtering, masking of forest coverage using band math, and geometric correction. A schematic diagram of the deforestation monitoring system is shown in Figure 3.

\subsection{Radiometric calibration}

Radiometric calibration is a primary step of SAR image processing. It allows the generation of imagery where a direct relation between pixel values and radar backscatter of the scene can be made. For this, the output scaling applied by the processor was reversed and the desired calibration scaling was performed. Sentinel-1A and Sentinel-1B products provide four calibration "Look Up Tables" (LUTs) to produce $\sigma_{0}, \beta_{0}, \gamma_{0}$ and to return to the "Digital Number"
(DN) (Schubert et al., 2015; Schwerdt et al., 2016; Schubert et al., 2017). To apply calibration to Ground Range Detected (GRD) products, we implemented the absolute calibration constant, and a constant offset, provided in the LUTs. Backscattering coefficient or Sigma Naught $\left(\sigma_{\mathrm{o}}\right)$ calibration was applied to extract surface areas of images as this facilitates a comparison of collected images at different time points. The sigma naught calibration was carried out using the following equation:

$\sigma_{0}=\frac{\mathrm{DN}^{2}}{\mathrm{~A}_{\sigma}^{2}}$

$\sigma_{0}$ and DN are provided in the LUTs and so using equation (1), we can compute the surface areas (i.e., $\mathrm{A}_{\sigma}{ }^{2}$ ).

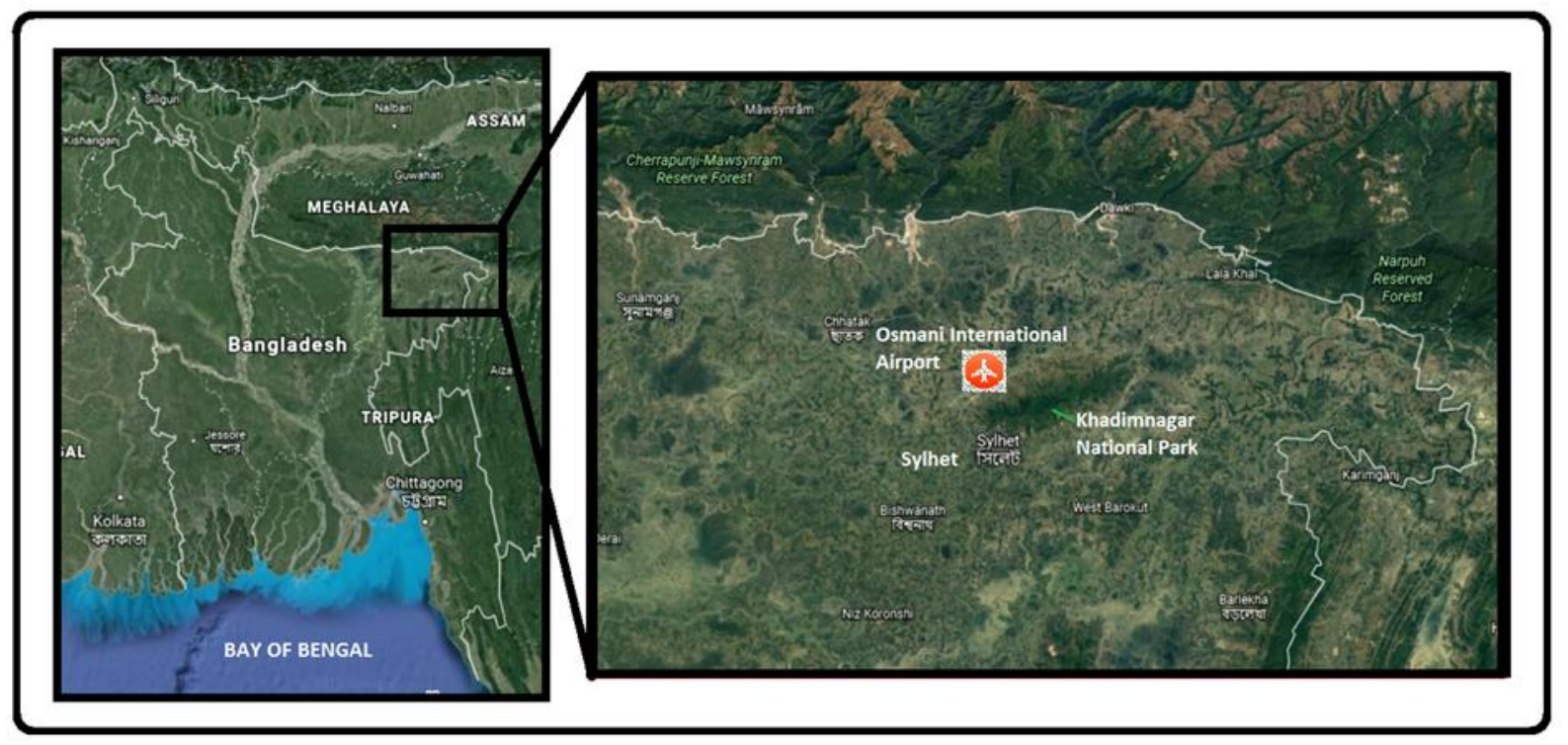

Figure 1: First area of interest: Khadimnagar National Park in NE Bangladesh.

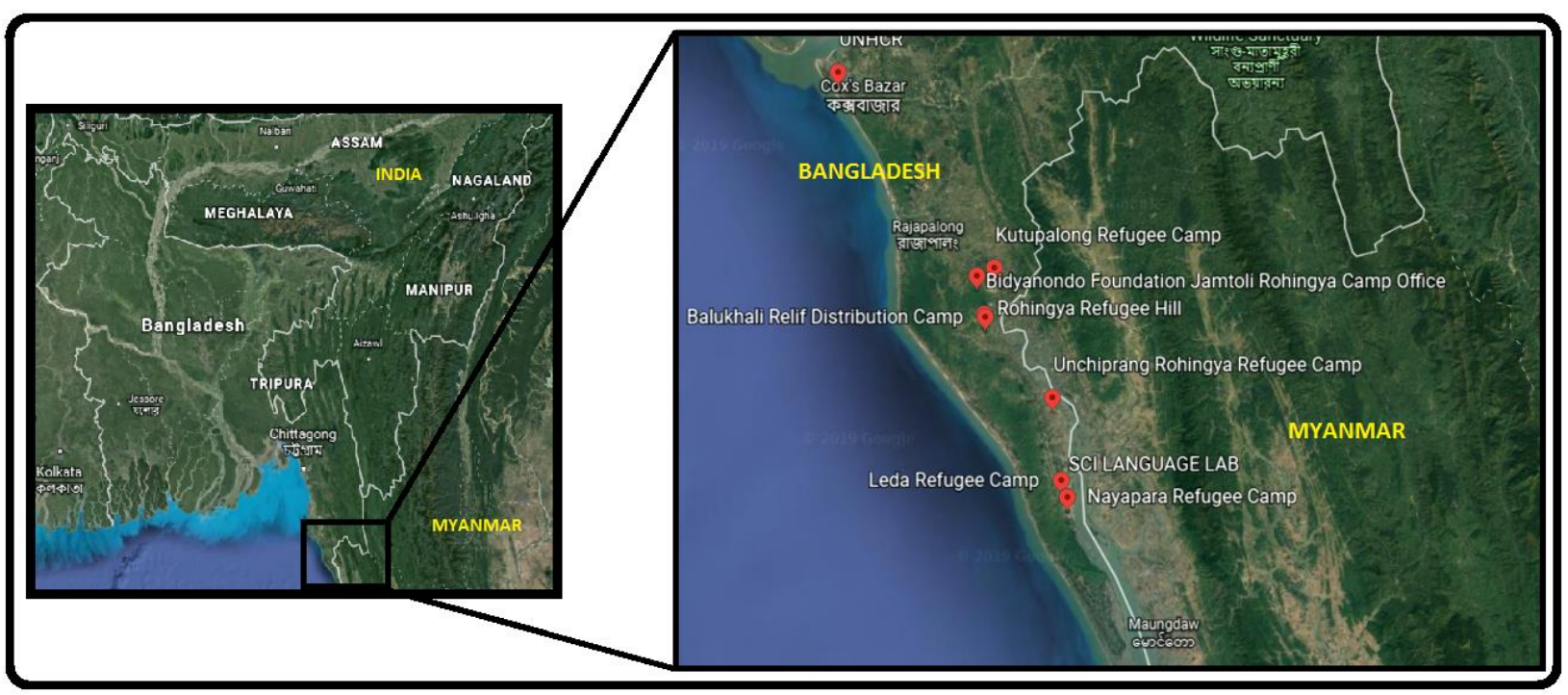

Figure 2: Second area of interest: Rohingya Camps in SE Bangladesh as of April 2018 


\subsection{Noise reduction}

Unlike optical radar images, SAR data are affected by speckle which is a multiplicative noise (Reimann et al. 2017) and reduction of such speckle noises is needed while maintaining image sharpness. For this Lee scalar speckle filtering method with a 5-pixel window was used instead of the Gaussian filter since the Lee filter preserves sharp edges of images while the latter makes images blurry, which makes identifying small deforested zones difficult (Mascarenhas, 1997; Rangayyan et al., 1998; Lee et al., 2006; Lee et al., 2009; Lee et al., 2015). Window size for the Lee filter is also very important and is basically application dependent (Lee et al., 1999; Lee et al., 2004). As the filter window size increases, speckle noises are reduced but images become smooth and lose sharpness (Lee et al., 2009; Lee et al., 2015). Several numerical trials were performed which revealed that the $5 \times 5$ ( 5 pixels) window size provided optimum results.

\subsection{Satellite image processing}

A simulated SAR image was then formulated with the Geometric terrain correction algorithm (the Digital Elevation Model (DEM) and orbit parameters of the satellite) applied to compensate for distortions due to topographical variations of a scene and the tilt of the satellite sensor. Then the real and the simulated SAR images were co-registered. Following this, the Range Doppler orthorectification method was implemented for geocoding the SAR images from single 2D raster radar geometry (Small et al., 2008) to derive the precise geolocation information.

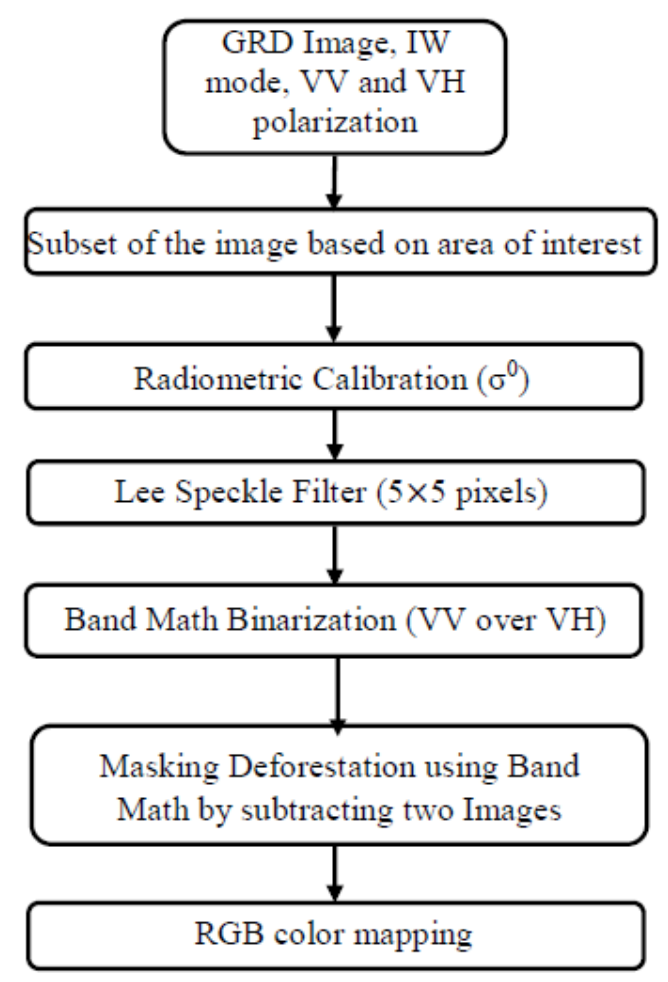

Fig. 3 Schematic diagram of the method used to investigate deforestation

\subsection{Band math application}

Finally, band math was applied to obtain the ratio between the $\mathrm{VH}$ and VV polarizations. In the first sub-study, an RGB color map was extracted to identify the different land types. To detect forest coverage, band math was applied to the processed images where the log band intensity range was between 0.02 and 0.085 . In the second sub-study, the log band intensity was converted to a linear band. The deforested areas were then identified by applying -2 to $-15 \mathrm{~dB}$ band math threshold values on the VH band. Finally, KMZ files were generated to visualize the deforested surface using "Google Earth". The visualized images have been interpreted in the result section.

\subsubsection{Sub-study 1}

For sub-study 1, after implementation of band math and all other processing steps, an RGB map was generated distinguishing different terrain and showing deforestation. After implementing band math masking, the output was given a value of 1 (white in the image) or 0 (black in the image). Forest coverages were subtracted (two dates) to assess deforestation which occurred in the study period. Areas without forestation were depicted in black while the forested areas were represented in white. The black color represented areas without forest while the white patches represented deforested areas.

\subsubsection{Sub-study 2}

For sub-study 2, images were prepared with forested areas represented in white and deforested in black. For further evaluation and determination of the exact deforested area, two images were collocated after band math masking. In this step, images from July 02, 2017, and April 22, 2018, were considered as master and slave images respectively. We compared the two masks by subtracting the master image from the slave image. Thus, the area of the deforested region was obtained. The masked areas were given the value of 1 (highlighted by white color) and all other areas were given the value of 0 (black). Care was taken in assigning master and slave images, as the master image is the reference image and should always be from an older date to detect deforestation. When detecting reforestation, the relatively new acquisition image (e.g., in this case, April 22, 2018) is considered the master and the older image (in this case, July 02, 2017), the slave. The final image was then superimposed on the AOI using Google Earth software to visualize the exact deforested location.

\subsection{Distinguishing natural and man-made deforestation}

In Bangladesh, besides man-made deforestation, natural deforestation may also occur due to events like floods in lowlying areas. The end products, after the application of our method, need to distinguish between natural and manmade deforestation. Therefore, land elevation was checked to rule out or bring into consideration natural deforestation related to flooding and this was also done using satellite data. DEMs for both AOIs were generated using two Single Look Complex 
satellite imageries from Sentinel-1 by interferogram and phase unwrapping (Gelautz et al. 2003). Additionally, meteorological data from the Bangladesh Meteorological Department (BMD) website was used as supporting evidence.

\subsection{Carbon release calculation for sub-study 2}

Carbon release from the study areas in Teknaf and Rajapalong was calculated adopting methods used by Islam et. al. (2011) and Turner et al. (1995). The procedure used here is briefly given below.

Carbon release and addition to atmosphere $=$ loss of carbon stock + loss in carbon uptake $\rightarrow$ converted to $\mathrm{Gg} \mathrm{CO}_{2}$.

- Loss of carbon stock in the deforested area:

$\mathrm{T}_{\mathrm{ave}} \times \mathrm{dFA} \times$ Tonnes dry mass-volume ratio $\times \mathrm{CFD}$

where $\mathrm{T}_{\text {ave }}=$ Average timber volume per unit area (timber density) in the forest.

The average volume of wood in Cox's Bazar district located in Chittagong Division was reported at $74.36 \mathrm{~m}^{3} / \mathrm{ha}$ (Choudhury and Hossain, 2011).

Tonnes dry mass-volume ratio $=0.625$ tons $/ \mathrm{m}^{3}$.

$\mathrm{CFD}=$ Carbon Fraction of Dry Biomass, which is 0.5

$\mathrm{dFA}=$ total deforested area

- Loss in carbon uptake (that which could have been sequestered had there been no deforestation):

$\mathrm{dFA} \times \mathrm{AG} \times \mathrm{CFD} \times$ No. of years

where $A G=$ Annual growth in tons/ha/year (tdm = ton dry mass), which is about 10.7 tons/ha-year (Islam et al., 2011).

The net carbon release was calculated by adding the two.

- This was then converted to Gg carbon dioxide using the formula weight of $\mathrm{CO}_{2}$ (44.1) which gives $1 \mathrm{Gg}$ carbon equivalent to $44.1 / 12 \mathrm{Gg}$ carbon dioxide.

\section{RESULTS}

\subsection{Sub-study 1: Deforestation at Khadimnagar, Sylhet}

Figures 4 and 5 show the RGB maps of the NE AOI (Sylhet), after implementation of band math and all other processing steps. Different land types such as Urban area (A), Airport runway (B), Forest (C), River (D) and flooded areas (E) are shown in these figures. Flooded areas are depicted in blue in these figures, as reported in Bhuiyan and Hoque (2020). The narrow blue line in Figure 4 shows the river in the dry period on March 14, 2017. The top part of Figure 4 shows the flood occurred due to the overflow of water from this river and connected the small lakes because of monsoon rains. In Figure 6, the area enclosed in the yellow oval in and around the national park, indicate deforestation, though not significant, that had occurred between March 14 and September 22 of 2017.

The DEM of the AOI (Figure 7) indicates the high elevated area is located from the south-west to north-east (blue to violet in the figure) while the other area (green color in the figure) are low-lying areas.
The red circled zone in Figure 6 is the core of the national park which is located at a slightly higher altitude (Figures 6 and 7). Additionally, the lack of significant white patches in Figure 6 indicates little deforestation. Here we also note that the white patches (Figure 6) in the bottom-left and top-right (yellow oval) (Figure 6) are in the flooded zone. This indicates possible flood-related deforestation. Thus, we can conclude that flooding in the AOI was responsible for the little deforestation that had occurred.

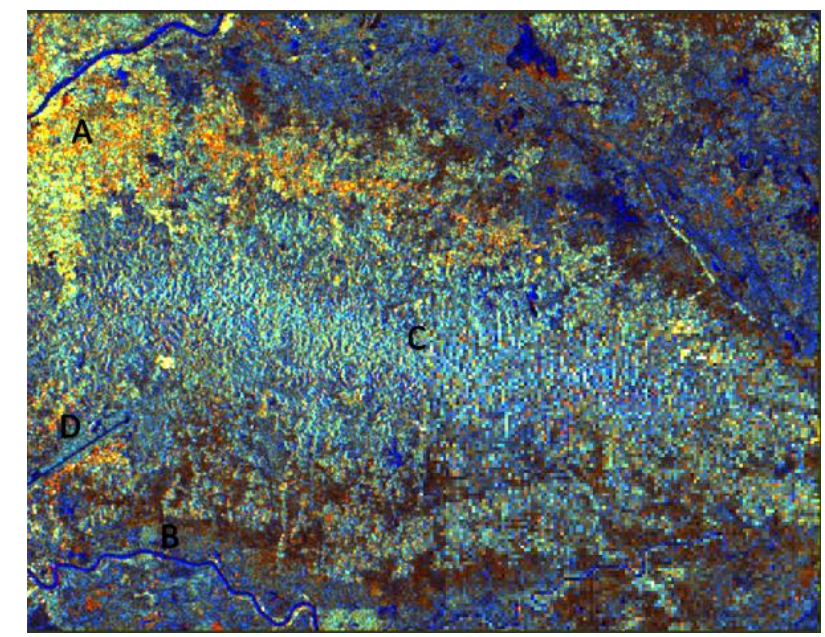

Fig. 4: RGB color map on March 14, 2017 (A, B, C, and D constitute an Urban area, Airport runway, Forest and River respectively).

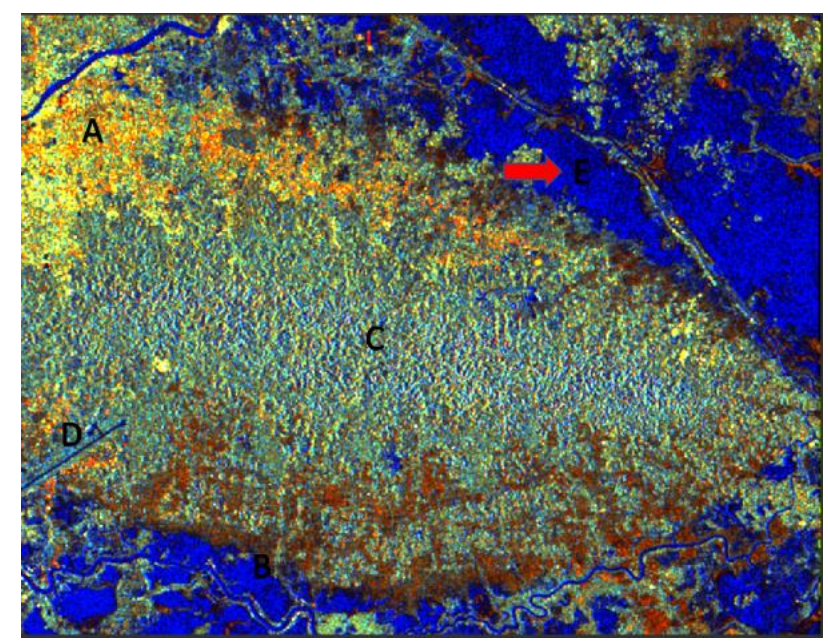

Figure 5: RGB color map on September 22, 2017 (A, B, C, $\mathrm{D}$, and $\mathrm{E}$ are an Urban area, Airport runway, Forest, River or and flooded area respectively). Notice that the airport runway (B) is flooded.

In this AOI, the forest had indeed gone underwater during a flooding episode, as reported in Bhuiyan and Hoque (2020). Out of $678.8 \mathrm{ha}, 80$ ha had been inundated and the flooding (green) was confined to the flanks in the north and the south. This resulted in the loss of trees, validating our findings.

\subsection{Sub-study 2: Deforestation at Teknaf and Rajapalong, Cox Bazar}

Deforestation in the southeast part of Bangladesh between July 2017 and April 2018 was studied using the same method 
and the final deforested region is shown in Figure 8. The white patches in Figure 8 represent deforestation region in the Cox's Bazar district.

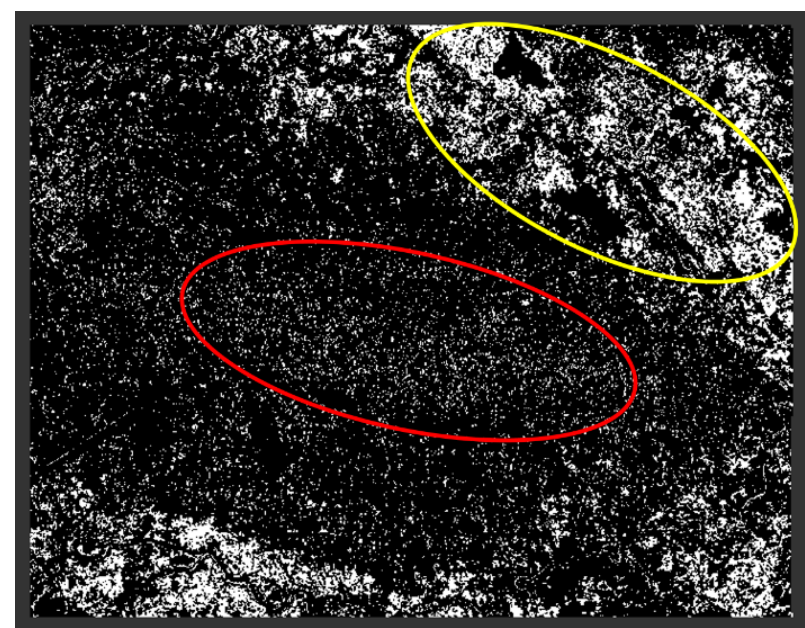

Fig. 6: The white-colored patches indicate deforested areas between March 14, 2017, and September 22, 2017. The area marked by the red oval is the core of the national park; it doesn't show significant deforestation. Deforestation in the yellow oval has occurred due to flooding in the area adjacent to the national park.

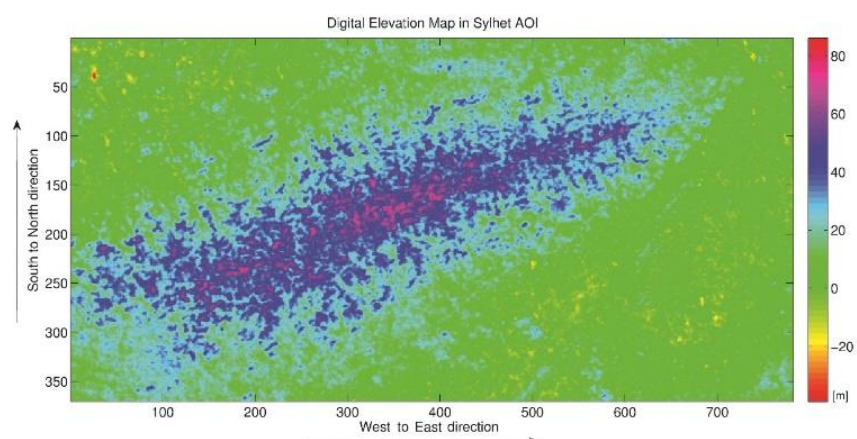

Fig. 7: Digital elevation map of the Sylhet AOI ranges from $40 \mathrm{~m}$ to $80 \mathrm{~m}$. The green color represents sea level while the blue to violet colors represent higher land.

In Sub-study 2, the cause of deforestation was tested by investigating meteorological data, collected from the Bangladesh Meteorological Department (BMD) website (BMD 2018) and the DEM of the area we prepared. No precipitation had occurred since April 21, 2018 (Figure 9) and during the month of April, the highest precipitation that had been recorded was $14 \mathrm{~mm}$ on April 14 and April 20, 2018, thus ruling out flood-related deforestation.

The DEM of the southeast is shown in Figure 10. The Bay of Bengal is on the left (red) and the hills are located on the right .(blue and purple). Teknaf and Rajapalong are highland areas, on average $300 \mathrm{~m}$ above sea level and the highest point is about 700 meters high (Figure 10). This also indicates that deforestation in this area was not due to temporal flooding as in the other AOI. Thus, we identified man-made, nonseasonal and massive deforestation in the second AOI.

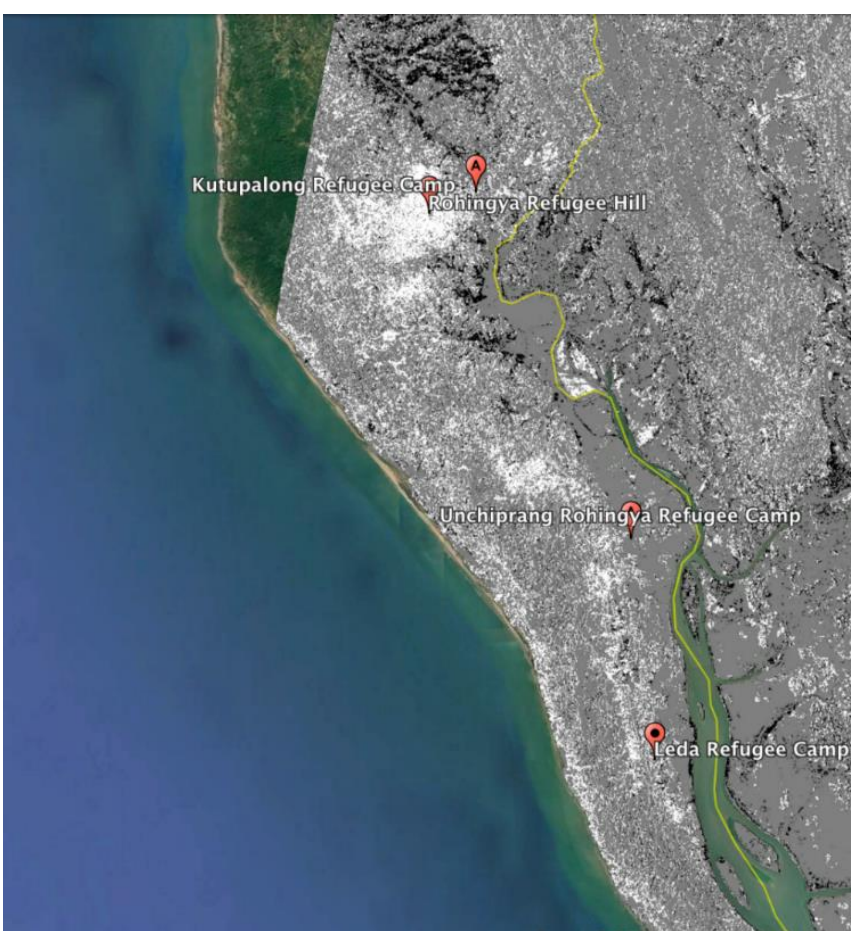

Figure 8: Deforested area (white color) of the Cox's Bazar district is overlaid on Google Earth. The locations of Kutupalong-Balukhali, Uchiprang, and Nayapara-Leda refugee camps are labeled.

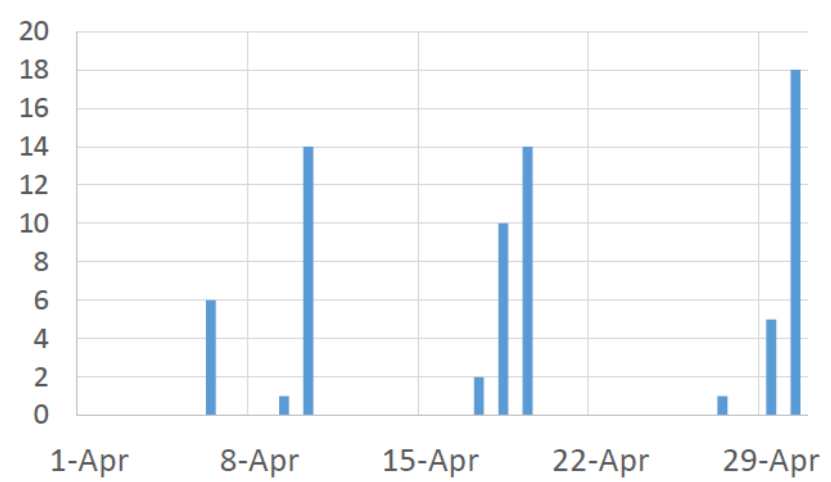

Fig. 9: Precipitation (in $\mathrm{mm}$ ) of Teknaf and Rajapalong in the month of April 2018.

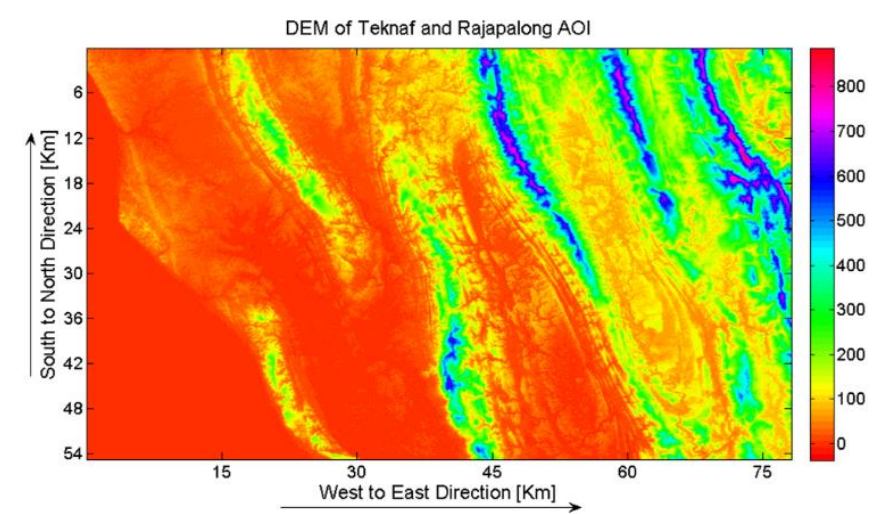

Fig. 10: DEM of the Teknaf and Rajapalong area with scale at the right. The Bay of Bengal is on the left and the hills are located on the right. 
Table 1: The loss of forest between July 2017 and April 2018 in three study sites: Kutupalong-Balukhali, Uchiprang, and Nayapara-Leda

\begin{tabular}{|c|c|c|c|c|c|}
\hline Study sites & $\begin{array}{c}\text { Defore } \\
\text { station } \\
\text { Rates } \\
\text { (\%) by } \\
\text { Sentin } \\
\text { el- 1A, } \\
\text { 1B }\end{array}$ & 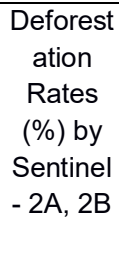 & $\begin{array}{c}\text { Buffer } \\
\text { zone }(\mathrm{km})\end{array}$ & $\begin{array}{c}\text { Defore } \\
\text { sted } \\
\text { area } \\
\text { (ha) }\end{array}$ & $\begin{array}{c}\text { Net } \\
\text { deforest } \\
\text { ation in } \\
\text { three } \\
\text { camp } \\
\text { areas } \\
\text { (ha) }\end{array}$ \\
\hline $\begin{array}{l}\text { Kutupalong- } \\
\text { Balukhali }\end{array}$ & 10.6 & 18 & 10 & 3328.4 & \multirow{3}{*}{3633.5} \\
\hline Uchiprang & 5.6 & 3 & 3.83 & 240.5 & \\
\hline $\begin{array}{l}\text { Nayapara- } \\
\text { Leda }\end{array}$ & 1.4 & 6 & 3.7 & 64.6 & \\
\hline
\end{tabular}

Significant deforestation (white color) was found near Rajapalong, where most Rohingya camps, including some of the new ones, are located (Figure 1 and Figure 8). The forest cover within the $6.2 \mathrm{~km}$ buffer zone created around the Kutupalong-Balukhali refugee camps shows a downward trend with a loss of 3328.4 ha: a decline of $10.6 \%$. Similarly, we found that between July 2017 and April 2018, the forest cover around Nayapara-Leda camp also declined by approximately 64.6 ha within the $3.7 \mathrm{~km}$ buffer zone (Table 1). The forest cover within the $3.83 \mathrm{~km}$ buffer zone created around the Uchiprang refugee camps similarly shows a downward trend. The deforested area was 240.5 ha or $5.6 \%$. Overall, the three sites studied indicate that the increasing population and settlement expansion in the forest areas caused substantial deforestation over the study period - a net deforestation of 3633.5 ha or over 36 square kilometers (14 square miles) around the three campsites.

\subsection{Net $\mathrm{CO}_{2}$ release/addition in Sub-study 2}

Using the equations given in the methods section, the total carbon release from the deforested area was calculated to be $99 \mathrm{Gg}$. This is equivalent to $363.8 \mathrm{Gg} \mathrm{CO}_{2}$. Brief calculations are shown below:

- Loss of carbon stock $=74.36 \mathrm{~m}^{3} / \mathrm{ha} \times 3633.5$ ha $\times 0.625$ tonnes $/ \mathrm{m}^{3} \times 0.5=84433.5$ tonnes of carbon or about $84.4 \mathrm{Gg}$ of carbon

- Loss in carbon uptake $=3633.5$ ha $\times 10.7$ tonnes/ha-year $\times$ $0.5 \times 9 / 12$ year $=14579.4$ tonnes $\cong 14.6 \mathrm{Gg}$

- Weight of $\mathrm{CO}_{2}=99 \mathrm{Gg} \mathrm{C} \times 44.1 / 12=363.825 \mathrm{Gg}$

\section{DISCUSSION}

Deforestation was identified near the three Rohingya refugee campsites in Kutupalong-Balukhali, Nayapara-Leda, and Uchiprang. We found substantial permanent deforestation in the study period marked by increasing population and settlement expansion in the forest areas.
It was also at an alarming level. The total area of forest in Cox Bazar was 30,398 ha (Choudhury and Hossain, 2011) and so a loss of 3,633.5 ha, revealed by our method and the Sentinel1A, 1B data collected between July 2017 and April 2018, represents a loss of over 10\%; a fact that is vitally important to the FD. This loss is about $0.16 \%$ on the national level. Thus, added to the usual annual loss of $0.18 \%$ the deforestation for 2017-2018 was probably almost double $(0.34 \%)$.

Hassan et. al. (2018) had also studied refugee camp expansion and deforestation in the same sites: Kutupalong-Balukhali, Uchiprang, and Nayapara-Leda, however, they only found 2283 ha of deforested areas in that region. This is because Hassan et al. (2018) showed deforestation only up to December 2017 while we assessed deforestation up to April 2018, accounting for the additional influx and logging activity of Rohingya refugees (Parveen et al., 2019).

This massive deforestation has grave implications for the environment and ecology of the country and if the trend is allowed to continue, irreparable damage may occur. Species loss (plant and animal) is the first concern and another major concern is the increase of greenhouse gases - in this case, carbon dioxide. Most of the wood from tree felling is being used as kindling in these areas by the refugees (Imtiaz, 2017). This releases the sequestered carbon as carbon dioxide into the atmosphere. Additionally, standing forests continue to sequester carbon from the atmosphere. This process is interrupted due to deforestation.

We computed the net emission and loss of continued sequestration of $\mathrm{CO}_{2}$ from the three campsites to be $84.4 \mathrm{Gg}$. The loss in continued carbon sequestration (uptake), had the three study sites not been deforested, was $14.6 \mathrm{Gg}$. Thus about $364 \mathrm{Gg} \mathrm{CO} 2$ was added to the atmosphere due to deforestation during the study period. This is an extremely alarming figure given that in 2018 the total carbon dioxide released from fossil fuel burning and industry was just 36.2 Gg (Levin, 2018).

\section{Conclusions}

In this study, the coverage of forest located in the northeast and southeast part of Bangladesh was monitored using freely available Sentinel-1 images. Sub-study 1 demonstrated the effective use of satellite imageries and data coupled with our method in distinguishing land type and identifying deforestation as well as determining cause and nature. In the second sub-study, data collected from the Cox Bazar district hill tracts for a period of 10 months were analyzed to identify deforestation caused by human activity and the alarming extent of damage in terms of area and carbon release. .So the freely available Sentinel-1imagery processed using our method can be used by the relevant authority to effectively and vigilantly track forests at very low cost and take effective steps in time. Given the extent of damage, the government may want to fund a bigger study to carry out monitoring activities of all forested regions by the team to demonstrate the efficacy of our method for eventual adoption. Finally, a 
committee versed in the method may be formed to help protect forest land and the environment in Bangladesh.

\section{ACKNOWLEDGMENTS}

This work was supported by ICT Division, Ministry of Posts, Telecommunications and IT, Government of the People's Republic of Bangladesh. The authors would like to thank Copernicus open access hub for collecting the Sentinel-1 data.

\section{REFERENCES}

BMD 2018 http://115.127.34.155:8080/DataLogger/\#query

Canadell J.G and Raupach M.R. (2008): Managing Forests for Climate Change Mitigation. Science 5882(320):14561457.

DOI: $\underline{10.1126 / \text { science. } 1155458}$

Dostálová A., Hollaus M., Milenković M., and Wagner W. (2016): Forest Area Derivation from Sentinel-1 Data, ISPRS Ann. Photogramm. Remote Sens. Spatial Inf. Sci., III-7, 227-233.

DOI: $\underline{10.5194 / \text { isprs-annals-III-7-227-2016 }}$

FAO (2015): Global Forest Resources Assessment 2015: Desk Reference, Food and Agriculture Organization of the United Nations Rome, Italy

Gelautz M., Paillou P., Chen C. W., Zebker H. A. (2003): Radar stereo- and interferometry-derived digital elevation models: comparison and combination using Radarsat and ERS-2 imagery. International Journal of Remote Sensing, 24, 24, 5243-5264.

DOI: $\underline{10.1080 / 0143116031000115139}$

Hassan M., Smith A., Walker K., Rahman M. and Southworth J. (2018): Rohingya refugee crisis and forest cover change in Teknaf, Bangladesh. Remote Sensing 10(5): 689.

DOI: $10.3390 / \mathrm{rs} 10050689$

Hoque, S.A. and Ahmed, T. Adapting the NeQuick 2 Model to GPS Derived TEC Data at a given Location. The AIUB Journal of Science and Engineering (AJSE) 15, no. 1 (2016): 135-141.

Hoque, S.N.M. A. (2016) Improvement of B2bot correction factor for NeQuick 2 during the high solar activity at Saint Croix. Journal of Advanced Research Design Volume 27, Issue 1 (2016) 19-26.

http://www.akademiabaru.com/doc/ARDV27_N1_P19_26.p df (Accessed on 12.19.2019)

Hoque, S.N.M.A. and Fenrich, F. (2018) A New Technique for Understanding Magnetosphere-Ionosphere Coupling Using Directional Derivatives of SuperDARN Convection Flow. Astrophys Astron. Volume 39, Issue 70.

DOI: $\underline{10.1007 / \mathrm{s} 12036-018-9561-2}$
Bhuiyan, M. M. I. and Hoque S.N.M. A. (2020) Flood monitoring and forecasting using SAR and meteorological data: A case study. Malaysian Journal of Fundamental and Applied Sciences. (Accepted for publication: October 2019. Vol 16 No 3)

Imtiaz S. (2018): Ecological impact of Rohingya refugees on forest resources: remote sensing analysis of vegetation cover change in Teknaf Peninsula in Bangladesh. Ecocycles 4(1): 16-19.

DOI: $10.19040 /$ ecocycles.v4i1.89

Islam K, Jashimuddin M, Nath B, Nath TK (2016) Quantitative Assessment of Land Cover Change Using Landsat Time Series Data: Case of Chunati Wildlife Sanctuary (CWS), Bangladesh. International Journal of Environment and Geoinformatics 3: 45-55.

DOI: $10.2139 /$ ssrn. 2819764

Islam M. J., Wagner T. W., Yichun X. and Mahboob M. G. (2011): Tropical Deforestation in Bangladesh and Global Warming. Proc. Int. Conf. Env. Aspects Bangladesh (ICEAB 2011)

Lee J S, Grunes M R and de Grandi G. (1999): Polarimetric SAR speckle filtering and its implication for classification. IEEE Transactions on Geoscience and Remote Sensing, 37(5):2363-2373.

DOI: $\underline{10.1109 / 36.789635}$

Lee J S, Grunes M R, Pottier E and Ferro-Famil L. (2004): Unsupervised terrain classification preserving polarimetric scattering characteristics. IEEE Transactions on Geoscience and Remote Sensing, 42(4):722-731.

DOI: $\underline{10.1109 / \text { TGRS.2003.819883 }}$

Lee J S, Grunes M R, Schuler D L, Pottier E and Ferro-Famil L. (2006): Scattering-model-based speckle filtering of polarimetric SAR data. IEEE Transactions on Geoscience and Remote Sensing, 44(1):176-187.

DOI: $\underline{10.1109 / \text { TGRS.2005.859338 }}$

Lee J. S., Wen J. H., Ainsworth T. L., Chen K. S., Chen A. J. (2009): Improved Sigma Filter for Speckle Filtering of SAR Imagery. IEEE Transactions on Geoscience and Remote Sensing. 47, 1, 202-213.

DOI: $\underline{10.1109 / T G R S .2008 .2002881}$

Lee J S, Ainsworth T L, Wang Y T and Chen K S. (2015): Polarimetric SAR speckle filtering and the extended sigma filter. IEEE Transactions on Geoscience and Remote Sensing, 53(3):1150-1160.

DOI: $10.1109 /$ TGRS.2014.2335114

Mason D. C., Trigg M, Pintado J. G, Cloke H. L., Neal J. C., Bates P D. (2016) Improving the TanDEM-X Digital Elevation Model for flood modelling using flood extents from Synthetic Aperture Radar images. Remote Sensing of Environment. 173, 15-28.

DOI: $\underline{10.1016 / \text { j.rse.2015.11.018 }}$ 
Mascarenhas N. D. A., edited by Shaun Quegan and Joao R. Moreira (1997): An Overview of Speckle Noise Filtering in SAR Images. Image Processing Techniques, First Latino- American Seminar on Radar Remote Sensing: Proceedings of a conference held 2-4 December 1996. Buenos Aires, Argentina, p.71

Potapov P., Siddiqui B. N., Iqbal Z., Aziz T., Zzaman B., Islam A., Pickens A., Talero Y., Tyukavina A., Turubanova S., Hansen M. C. (2017): Comprehensive monitoring of Bangladesh tree cover inside and outside of forests, 20002014. Environmental Research Letters, 104015, 10, 12, $1748-9326$.

DOI: $\underline{10.1088 / 1748-9326 / \mathrm{aa} 84 \mathrm{bb}}$

Quegan S., Toan T.L., Yu J.J., Ribbes F. and Floury N. Multitemporal ERS SAR Analysis Applied to Forest Mapping. IEEE Transactions on Geoscience and Remote Sensing. 2000; 38(2), 741-753.

DOI: $\underline{10.1109 / 36.842003}$

Rahman M. F., Jashimuddin M, Kamrul Islam, Kumar Nath T (2016): Land Use Change and Forest Fragmentation Analysis: A Geoinformatics Approach on Chunati Wildlife Sanctuary, Bangladesh. J Civil Eng Environ Sci 2(1): 020-029.

DOI: $10.17352 / 2455-488 X .000010$

Rahman M. M. and Sumantyo J. T. S. Mapping tropical forest cover and deforestation using synthetic aperture radar (SAR) images. Applied Geomat. 2010; 2:113-121.

DOI: $10.1007 / \mathrm{s} 12518-010-0026-9$

Rahman M.Z. (2018): Livelihoods of Rohingyas and Their Impacts on Deforestation. In: Tani M., Rahman M. (eds) Deforestation in the Teknaf Peninsula of Bangladesh. Springer, Singapore.

DOI: $10.1007 / 978-981-10-5475-4 \quad 9$

Rangayyan R. M., Ciuc M., Faghih F. (1998): Adaptiveneighborhood filtering of images corrupted by signaldependent noise. Appl. Opt. 37, 4477-4487.

DOI: $10.1364 / \mathrm{AO} .37 .004477$
Reimann J., Schwerdt M., Schmidt K., Tous Ramon N., Döring B (2017): The DLR Spaceborne SAR System Calibration Center. Frequenz. 2017.

DOI: $10.1515 /$ freq-2016-0274

Schubert A, Small D, Miranda N, Geudtner D, Meier E. (2015): Sentinel-1A Product Geolocation Accuracy: Commissioning Phase Results. Remote Sensing. 7(7):9431-9449.

DOI: $\underline{10.3390 / \mathrm{rs} 70709431}$

Schubert A, Miranda N, Geudtner D, Small D. (2017): Sentinel-1A/B Combined Product Geolocation Accuracy. Remote Sensing. 9(6):607.

DOI: $10.3390 / \mathrm{rs} 9060607$

Schwerdt M., Schmidt K., Tous Ramon N., Castellanos Alfonzo G., Döring B., Zink M., Prats P. (2016): Independent Verification of the Sentinel-1A System Calibration: IEEE J. Sel. Top. Appl. Earth Obs. Remote Sens. 9, 994-1007.

DOI: $10.3390 / \mathrm{rs} 9060511$

Sentinel-1 (2017) https://scihub.copernicus.eu/dhus/ (Accessed April 01, 2017)

Small D., Schubert A. (2008) Guide to ASAR Geocoding, RSL-ASAR-GC-AD, Issue 1.0

SNAP (2018) http://step.esa.int/main/download/ version 5.0 (Accessed January 10, 2018)

Turner, D.P., Koerper, G.J., Harmon, M.E., Lee, J.J., 1995. Carbon sequestration by forests of the United States. Current status and projections to the year 2040. Tellus B Chem. Phys. Meteorol. 47, 232-239.

DOI: $10.3402 /$ tellusb.v47i1-2.16043

Wagner W., Luckman A., Vietmeier J., Tansey K., Balzter H., Schmullius C., Davidson M., Gaveau D., Gluck M., Toan T.L., Quegan S., Shvidenko A., Wiesmann A. and Yu J.J. (2003): Large-scale mapping of boreal forest in Siberia using ERS tandem coherence and JERS backscatter data. Remote Sensing of Environment, 85, 125-144.

DOI: $10.1016 / \mathrm{S} 0034-4257(02) 00198-0$ 